\title{
Influence of Catalyst Preparation Conditions on Coconut Shell-derived Solid Acid Catalyst Performance for Transesterification
}

\author{
S. H. Y. S Abdullah, A. Endut, F. Lananan
}

\begin{abstract}
The carbon-based solid acid catalyst is mostly synthesized through a series of incomplete carbonization and sulfonation process. This paper investigates the influence of catalyst preparation conditions on the catalyst performance in biodiesel conversion. Coconut-shell-derived solid acid catalyst was prepared through incomplete carbonization followed by sulfonation using concentrated sulphuric acid. The effect of catalyst preparation variables including carbonization temperature, carbonization time, sulfonation temperature and sulfonation time was evaluated using response surface methodology. The adequacy of the mathematical model represents the process was confirmed by using ANOVA analysis with $R 2$ value of 0.9121 and p-value $<0.0001$. Optimal process conditions were obtained at carbonization temperature of 469.97 ${ }^{\circ} \mathrm{C}$, carbonization time of $3.37 \mathrm{~h}$, sulfonation temperature of $99.14{ }^{\circ} \mathrm{C}$ and sulfonation time of $7.11 \mathrm{~h}$. At these conditions, the coconut shell-derived catalyst able to catalyse the transesterification reaction and achieved $>80 \%$ FAME conversion. This study uncovers the potential of biomass valorisation into a useful end produc.

Index Terms:- Biodiesel, coconut shell, optimization, response surface methodology, solid acid catalyst.
\end{abstract}

\section{INTRODUCTION}

Biodiesel or fatty acid methyl ester (FAME) is the result alcohol with or without the presence of catalyst [1]. The similar chemical structure of biodiesel and petroleum diesel allows it to be used as a fuel source. In addition, biodiesel produced less emission, non-toxic and biodegradable [2]. The application of biodiesel could contribute to reducing the impact of global warming [3]-[7].

The solid acid catalyst is known for their insensitivity towards the water and free fatty acid (FFA), hence making it suitable options for high FFA feedstock such as waste cooking oil [8]. On top of that, the catalyst can be easily removed by simple filtration and recycled for the next cycle [9]. The application of biomass as a source of precursor carbon for the solid acid catalyst is widely discussed [10], [11]. Biomass is low cost, readily available with high carbon content make it a suitable starting material for solid acid catalyst development [12]. In this study, coconut shell was used as the precursor carbon for solid acid catalyst development. Coconut (Cocos nucifera) shell is one of the

S. H. Y. S Abdullah, Faculty of Innovative Design and Technology, Universiti Sultan Zainal Abidin, Gong Badak Campus, 21300 Kuala Terengganu, Terengganu, Malaysia

A. Endut, Faculty of Innovative Design and Technology, Universit Sultan Zainal Abidin, Gong Badak Campus, 21300 Kuala Terengganu, Terengganu, Malaysia.

F. Lananan, Faculty of Bioresources and Food Industry, Universiti Sultan Zainal Abidin, Tembila Campus, 22200 Besut, Terengganu, Malaysia of a chemical reaction between plant oils/animal fats with

Revised Manuscript Received on July 10, 2019.

main agricultural wastes in Malaysia. In 2009, a total estimation of 0.459 million tons of coconut was produced in Malaysia. This has resulted in a significant amount of biomass including coconut husk (0.1666 million tons) coconut shell $(0.735$ million tons) coconut frond $(0.103$ million tons) and empty bunches (0.0022 million tons) [13], [14].

Response surface methodology (RSM) is a mathematical tool that is widely used for process optimization [15]. This method uses a fit of a mathematical model to the experimental result to describe the process. The model can be used for optimization, predictions or interpretation. The use of RSM has improved process performance by reducing the number of variables, reducing operational cost and experimental time [16].

In the synthesis of solid acid catalyst from the carbon source, the combined method of carbonization and sulfonation is often used (REF1, REF2). This method uses a mild operating condition which reduces the energy and cost required to produce a catalyst (REF3). Nevertheless, both carbonization and sulfonation presented a significant effect on the performance of a solid catalyst by altering the surface porosity and acid density of the developed carbon catalyst. Hence, the present study aims to investigate the influence of catalyst preparation conditions on the catalytic performance solid acid catalyst derived from coconut shell. The effect of catalyst preparation conditions including carbonization temperature, carbonization time, sulfonation temperature and sulfonation time were evaluated using RSM methodology. In addition, optimization study was carried out to determine the optimal solutions for catalyst preparation conditions.

\section{MATERIALS AND METHOD}

\section{A. Raw Materials}

Coconut shell biomass was obtained from local market. Palm oil (BURUH) was purchased from local grocery store. All the chemicals used in this study are reagent grade including concentrated sulfuric acid (Merck, 98\%), methanol (Merck) and sodium hydroxide (Merck, $\geq 97 \%$ ), hydrochloric acid (Sigma-Aldrich, 37\%), sodium chloride (Sigma-Aldrich, $\geq 99.5 \%$ ) and potassium hydroxide SigmaAldrich, ( $\geq 85 \%)$.

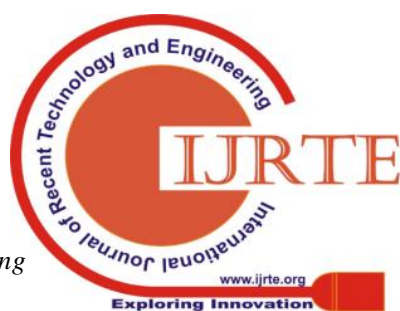




\section{INFLUENCE OF CATALYST PREPARATION CONDITIONS ON COCONUT SHELL-DERIVED SOLID ACID CATALYST PERFORMANCE FOR TRANSESTERIFICATION}

\section{B. Catalyst Synthesis}

The catalyst was synthesized according to a method described in [17]. Coconut shell biomass was primarily washed with distilled water and sun-dried for $24 \mathrm{hr}$. The biomass was then subjected to oven-drying at $100{ }^{\circ} \mathrm{C}$ for 12 $\mathrm{h}$ to remove moisture. About $20 \mathrm{~g}$ of the precursor carbon catalyst was incompletely carbonized in a muffle furnace under constant nitrogen flow at the specific temperature and time. The carbonized sample was then ground in a laboratory mortar to form a fine powder. The powder was sieved using $100 \mu \mathrm{m}$ sieve to obtain uniform size $(0.5-1$ $\mathrm{mm})$. Sulfonation was carried out by mixing $10 \mathrm{~g}$ carbon catalyst with $100 \mathrm{~mL} \mathrm{H}_{2} \mathrm{SO}_{4}$ in a $100 \mathrm{~mL}$ conical flask for 15 min. Excess acid was removed. The residual wet solids (the mixture of carbon and acid) were then transferred to a ceramic crucible placed in a muffle furnace and heated at the specific temperature and time. After cooling to ambient temperature, the carbonized sample was cooled and rinsed with deionized water until the filtrate was neutral in $\mathrm{pH}$ and free from sulphate ions. Following filtration, the sample was dried at $105{ }^{\circ} \mathrm{C}$ for $10 \mathrm{~h}$ in an air-drying oven. Solid acid catalyst (SAC) was kept in an air-tight container to prevent contamination.

\section{Catalyst Characterization}

The morphology of the prepared activated carbon (AC) and SAC was characterized by means of scanning electron microscopy (SEM) at $17 \mathrm{kV}$ (JEOL Ltd., Japan, model JSM 6700F). Thermo-gravimetric analysis (TGA) and differential scanning calorimetry (DSC) was performed to assess the thermal stability of prepared catalyst at the high-temperature condition. TGA and DSC analysis were conducted using Lab Mettler TGA analyzer (SAR SW 12.10) in a platinum crucible, under an argon atmosphere $(50 \mathrm{~mL} / \mathrm{min})$ from 30 to $900{ }^{\circ} \mathrm{C}$ with an increasing temperature rate of $10{ }^{\circ} \mathrm{C} / \mathrm{min}$. The surface functional groups of the carbon precursor and solid acid catalyst were determined using Fourier Transform Infrared (FTIR) spectroscopy (Shimadzu IR Prestige 21) analysis. Nitrogen adsorption-desorption isotherms on prepared catalyst were carried out using an automatic adsorption unit, Micromeritics, MicroActive 3.0.0. Acidbase back titration method was performed to measure the surface acid density of the SAC samples.

\section{Catalyst Activity}

The catalytic activity of the SAC was evaluated using transesterification of palm oil. The reaction was carried out using method described in [18]. Reaction was conducted in a $50 \mathrm{~mL}$ centrifuge tube filled with $2 \mathrm{~g}$ of vegetable oil. Methanol and solid acid catalyst were added into the reaction. Centrifuge tubes were kept in an incubator shaker at a constant temperature of $60{ }^{\circ} \mathrm{C}$ and a stirring rate of 200 $\mathrm{rpm}$ as these provided non-limiting conditions. Once the reaction was concluded, the tubes were immediately cooled to room temperature. The biomass was separated from the liquid by vacuum filtration. The liquid product was heated in an oven $\left(60-70{ }^{\circ} \mathrm{C}\right)$ or rotary evaporator to remove excess methanol, and settled in a separating funnel. The upper phase contained biodiesel whilst the lower phase consisted of glycerol by-product. The liquid (containing methanol, FAME and by-products) was stored in pre-weighed tubes.
The final weight of the liquid was recorded for each tube. The experiments were conducted in triplicate.

\section{Optimization Study}

The optimization for catalyst preparation conditions was conducted using Central Composite Design (CCD) by RSM. A four-factor-three-level design was chosen in the modelling and optimization study which generated 30 experimental runs with 6 replications of the centre point. The coded and actual factors are shown in Table 1 while the CCD arrangement was displayed in Table 2.

Table 1: Coded and actual factor for SAC preparation conditions using CCD

\begin{tabular}{|c|c|c|c|c|}
\hline \multicolumn{2}{|c|}{ Factor } & \multicolumn{3}{|c|}{ Level } \\
\hline Coded & Actual & -1 & 0 & +1 \\
\hline $\mathrm{X}_{1}$ & $\begin{array}{c}\text { Carbonization } \\
\text { temperature }\left({ }^{\circ} \mathrm{C}\right)\end{array}$ & 400 & 500 & 600 \\
\hline $\mathrm{X}_{2}$ & Carbonization time (h) & 2 & 4 & 6 \\
\hline $\mathrm{X}_{3}$ & $\begin{array}{c}\text { Sulfonation } \\
\text { temperature }\left({ }^{\circ} \mathrm{C}\right)\end{array}$ & 50 & 100 & 150 \\
\hline $\mathrm{X}_{4}$ & Sulfonation time (h) & 6 & 8 & 10 \\
\hline
\end{tabular}

Table 2: CCD arrangement for SAC preparation conditions

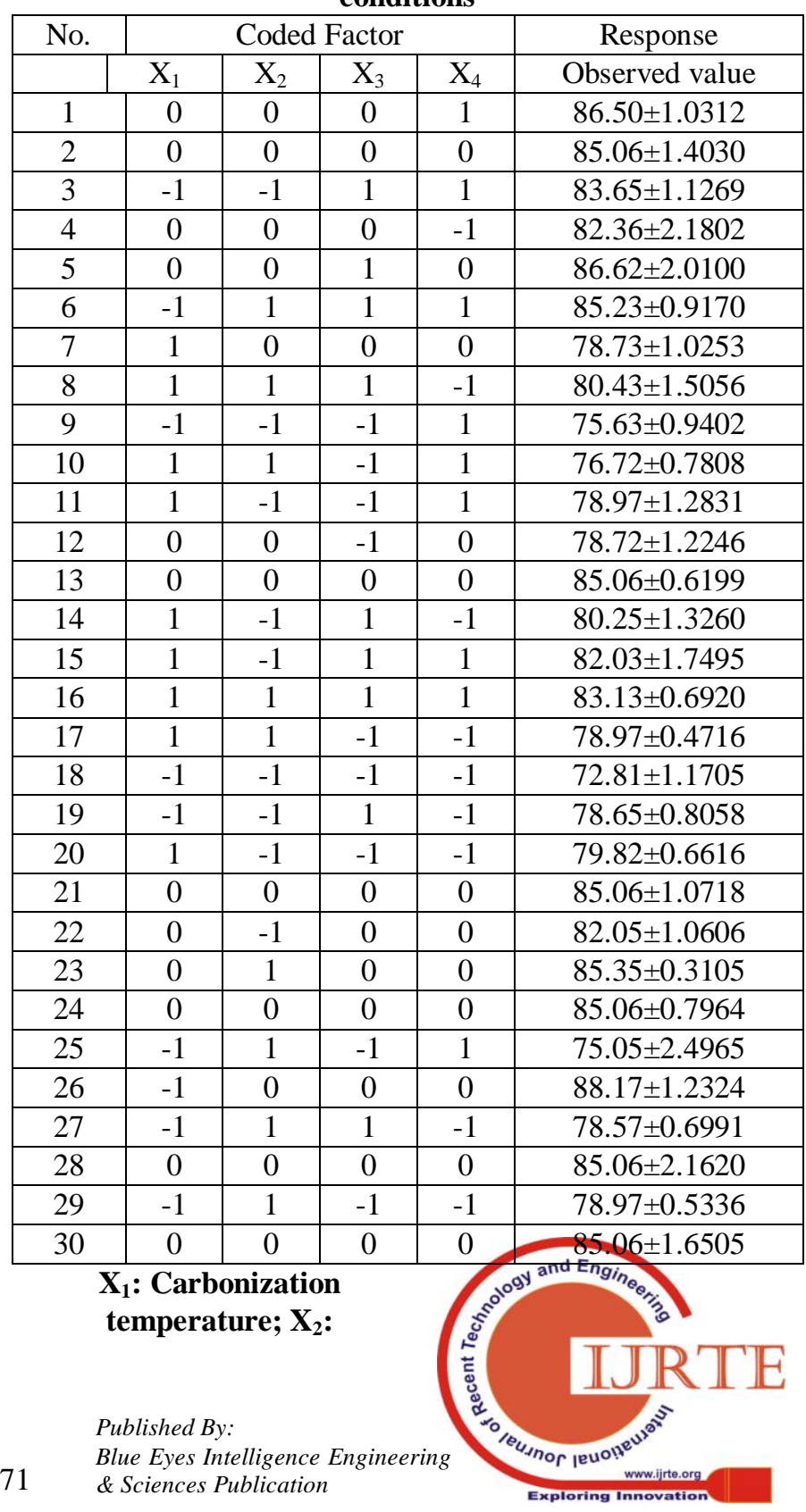




\section{Carbonization time; $\mathbf{X}_{3}$ : Sulfonation temperature; $\mathbf{X}_{4}$ :} Sulfonation time

The conversions of biodiesel were analysed through multiple regressions by plotting into a second-order polynomial in (1) as follows:

$Y=\beta_{0}+\beta_{1} X_{1}+\beta_{2} X_{2}+\beta_{3} X_{3}+\beta_{12} X_{1} X_{2}+\beta_{13} X_{1} X_{3}+\beta_{23} X_{2} X_{3}$ $+\beta_{11} X_{1}^{2}+\beta_{22} X_{2}^{2}+\beta_{33} X_{3}^{2}$

where $Y$ is the biodiesel conversion, $\beta_{0}$ is the intercept term, $\beta_{1}, \beta_{2}$ and $\beta_{3}$ are the linear coefficients, $\beta_{12}, \beta_{12}$ and $\beta_{13}$ are the interactive coefficients, $\beta_{11}, \beta_{22}$ and $\beta_{33}$ are the quadratic coefficients, and $X_{1}, X_{2}$ and $X_{3}$ are the coded independent variables. Design Expert 7.0.0 software (StatEase Inc., Minneapolis, USA) was used for regression analysis of experimental data and response surface plots.

\section{RESULTS AND DISCUSSION}

\section{A. Characterization of Solid Acid Catalyst}

Fig. 1 shows the SEM images of AC after the carbonization process and SAC following the sulfonation with concentrated sulphuric acid. From observation, the presence of pores is visible on the surface of both $\mathrm{AC}$ and SAC. Carbonization has led to the pore formation on the AC surface due to the release of volatile gases [19]. The pore distribution in SAC was not affected by the strong remark for a good catalyst is that the structure of a carbon material retained with a uniform distribution of impregnated material upon modification.

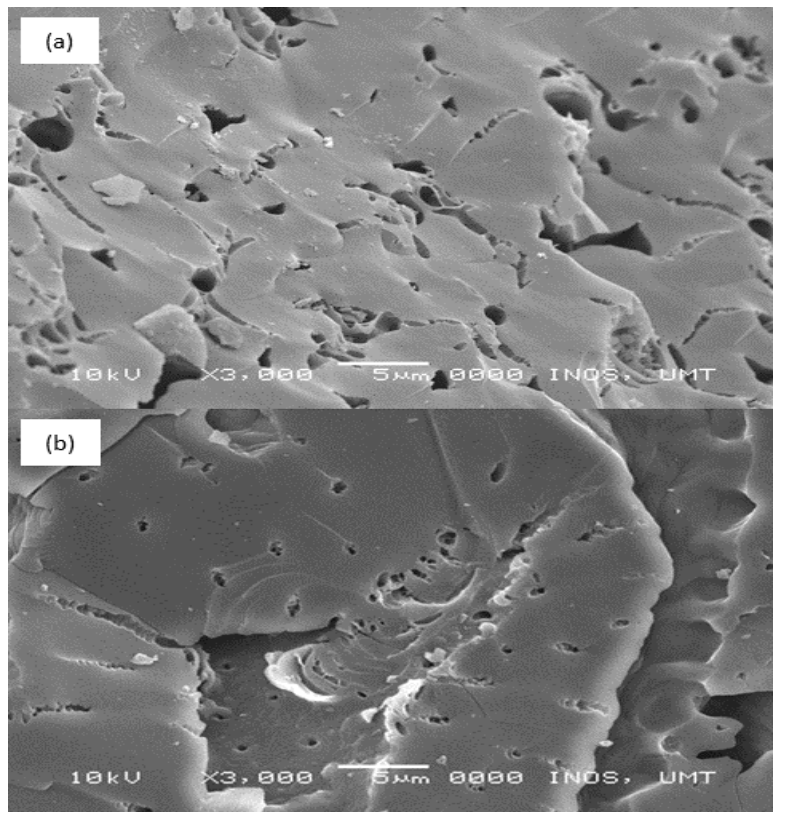

Fig. 1: SEM images of coconut shell-derived (a) AC and (b) SAC

The thermal stability of both AC and SAC was evaluated by DSC analysis (Fig. 2a) and TGA analysis (Fig. 2b). Both samples presented a similar two-step weight loss in TGA analysis. Initial weight loss was observed at the region $<200$ sulfonation process. In [20] reported that an important

${ }^{\circ} \mathrm{C}$ in both $\mathrm{AC}$ and SAC with $8.7 \%$ and $7.3 \%$ respectively due to the removal of adsorbed water molecules retained in the samples [21]. This finding is supported by the presence of a prominent peak in the heat flow in the DSC curve at this region.

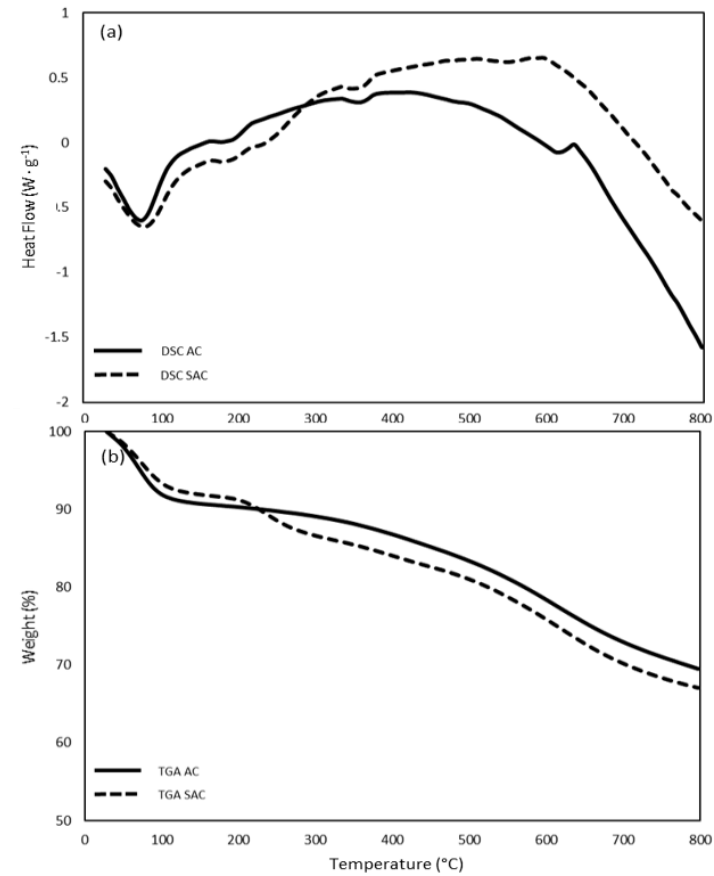

Fig. 2: (a) DSC and (b) TGA curves of AC and SAC from 30 to $800{ }^{\circ} \mathrm{C}$

The second step weight reduction was observed at the region above $350{ }^{\circ} \mathrm{C}$ where a continuous and steep mass loss was observed up to $800{ }^{\circ} \mathrm{C}$. This significant mass loss can be correlated to the decomposition of and removal of carbonaceous species mainly as $\mathrm{CO}_{2}$ and volatile matter [22]. Higher weight loss was observed in SAC due to the incorporation of the sulfonic group onto the catalyst surface. A similar finding was reported in the previous study which involved sulphur-impregnated carbon compound [23].

Evaluation of the surface chemistry of SAC confirmed the presence of sulfonic groups in the catalyst body (Fig. 3). At low spectrum region, peaks at 516 and $694 \mathrm{~cm}-1$ indicate the S-S stretching and C-S stretching that can be found in sulphur compounds [24]. In addition, a sharp peak was observed at $1066 \mathrm{~cm}-1$ that represents $\mathrm{S}=\mathrm{O}$ stretching. Upon sulfonation, the strong absorption band at $1284 \mathrm{~cm}-1$ and absorption band at $1153 \mathrm{~cm}-1$ appeared according to $\mathrm{SO}_{2}$ asymmetric and symmetric stretching, respectively [19] , [25]. This indicated that the sulfonic $\left(-\mathrm{SO}_{3} \mathrm{H}\right)$ groups are linked to the amorphous carbon structure in the form of C$\mathrm{O}-\mathrm{SO}_{3} \mathrm{H}[26]$.

The textural properties of $\mathrm{AC}$ and $\mathrm{SAC}$ were presented in Table 3. The porosity of SAC is reduced after the sulfonation process as compared to AC. The sulfonation process has led to the reduction in catalyst surface area from 197.6232 to $134.1925 \mathrm{~m}^{2} / \mathrm{g}$ in BET surface area and 112.49 to $35.416 \mathrm{~m}^{2} / \mathrm{g}$ in total pore area. In addition, a reduction in the total pore volume was also noticed from 0.07491 to $0.05314 \mathrm{~cm}^{3} / \mathrm{g}$.

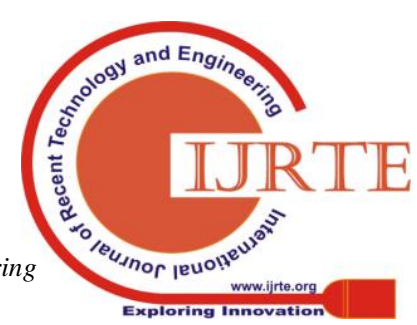




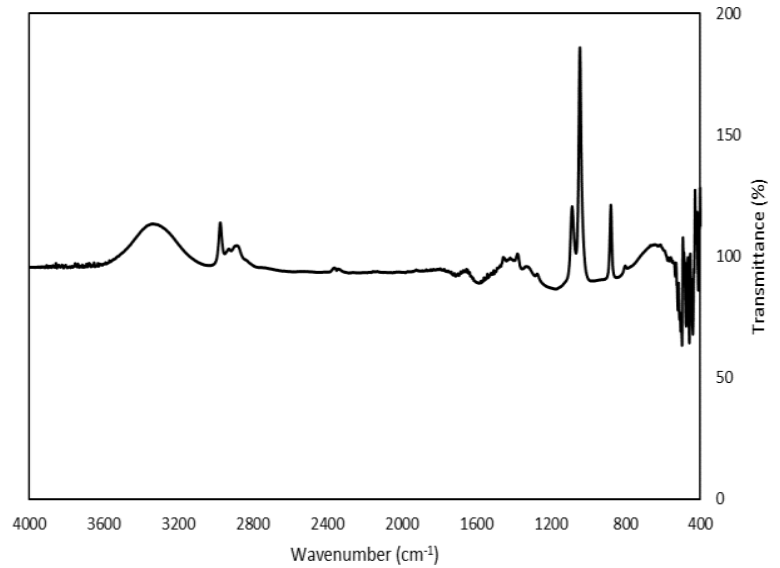

Fig. 3: FTIR Spectrum of SAC derived from coconut shell

However, sulfonation has resulted in an increase in the pore size from $18.0646 \AA$ to $18.9510 \AA$. This might be due to intercalation of sulfonic group in the carbon sheet of coconut shell which occurred on the surface and thus reduced the surface area of the derived catalyst. This result was supported by the previous finding by [27] where sulfonation resulted in the reduction in surface area of microcrystalline cellulose derived catalyst. In another study, in [28] stated that the shrinkage of structure and broken bond are the effects of the penetration of strong acid groups on the surface of the catalyst. High catalyst yield was observed $(94 \%)$ indicated the high potential of coconut shell as precursor carbon for solid catalyst development. In addition, a high sulfonic acid density of SAC $(0.51 \mathrm{mmol} / \mathrm{g})$ as presented in Table 3 also an indicator that the developed catalyst is highly active with a high number of the acidic active site available for the reaction.
Table 3: Catalyst yield and textural properties of SAC

\begin{tabular}{|c|c|c|}
\hline Parameter & AC & SAC \\
\hline Catalyst yield $(\%)$ & ND & $94.36 \pm 0.32$ \\
\hline $\begin{array}{c}\text { Sulfonic acid density } \\
(\mathrm{mmol} / \mathrm{g})\end{array}$ & ND & $0.51 \pm 0.11$ \\
\hline BET surface area $\left(\mathrm{m}^{2} / \mathrm{g}\right)$ & 197.623 & 134.1925 \\
\hline Pore size $(\AA)$ & 18.0646 & 18.9510 \\
\hline Total pore volume $\left(\mathrm{cm}^{3} / \mathrm{g}\right)$ & 0.0749 & 0.0531 \\
\hline Total pore area & 112.49 & 35.416 \\
\hline
\end{tabular}

\section{B. ANOVA Analysis}

A quadratic model to predict the conversion given by RSM is presented in (2). The model Eq. that corresponds the response to the independent variables is summarized in terms of coded value.

$Y(\%)=85.02+0.39 X_{1}+0.55 X_{2}+2045 X_{3}+0.82 X_{4}-$ $0.63 X_{1} X_{2}-0.85 X_{1} X_{3}-0.49 X_{1} X_{4}+0.098 X_{2} X_{3}-0.43 X_{2} X_{4}+$ $1.19 X_{3} X_{4}-1.52 X_{1}^{2}-1.27 X_{2}^{2}-2.30 X_{3}^{2}-0.54 X_{4}^{2}$

where $Y$ is the FAME conversion, $X_{I}$ is the carbonization temperature, $X_{2}$ is the carbonization time, $X_{3}$ is the sulfonation temperature and $X_{4}$ is the sulfonation time. ANOVA analysis was conducted to evaluate the statistical significance of the quadratic model and the result was summarized in Table 4. The model $F$-value of 11.12 and $p$ value of $<0.0001$ indicated that the model was statistically significant at a $95 \%$ confidence interval. Value of $\mathrm{p}$-value which is less than 0.05 indicates that model terms are significant, while values greater than 0.1 indicate that the model terms are not significant.

Table 4: Analysis of variance for the second order polynomial model

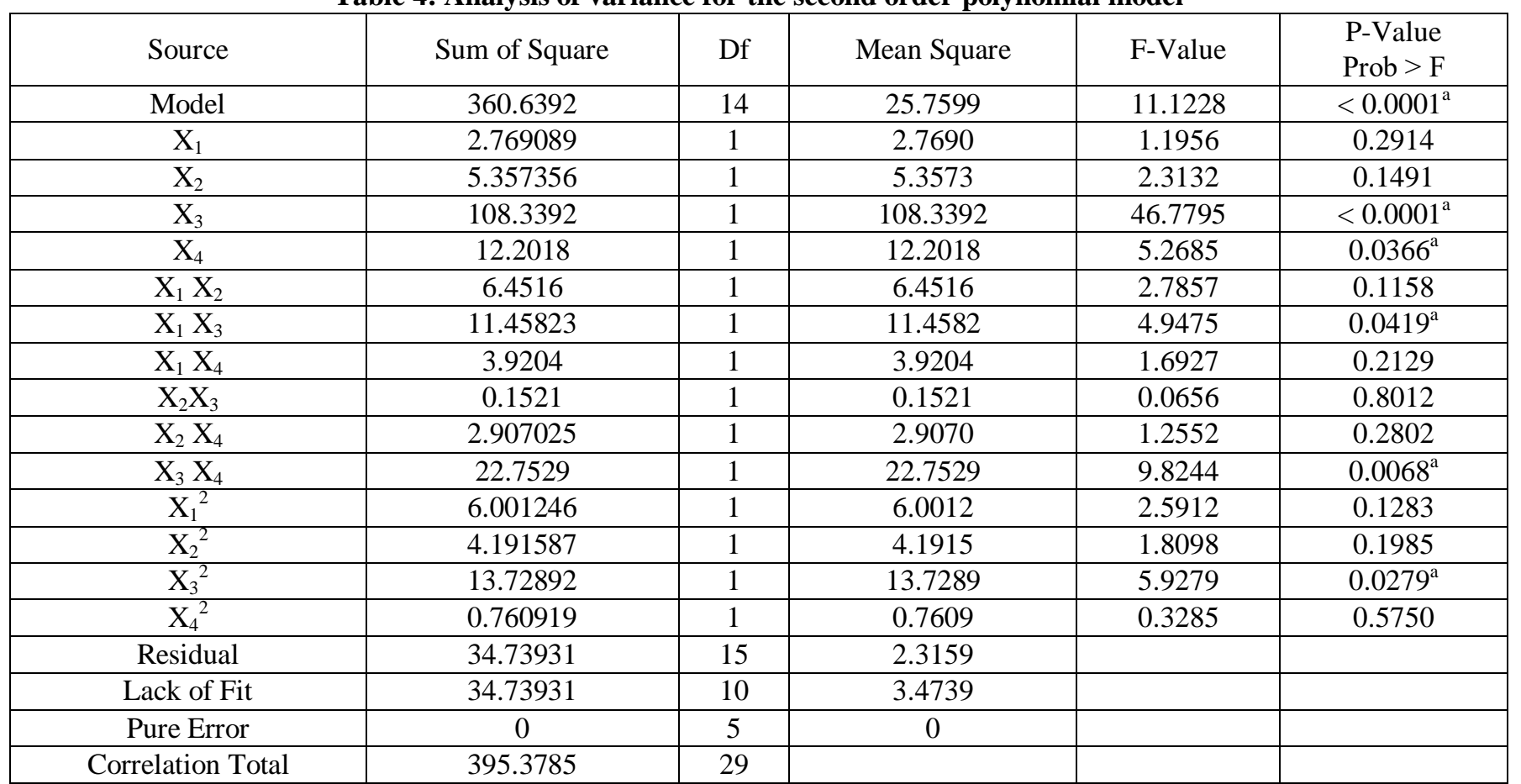

${ }^{\text {a }}$ Statistically significant at $95 \%$ confidence level.

$\mathrm{X}_{1}$ : carbonization temperature, $\mathrm{X}_{2}$ : carbonization time, $\mathrm{X}_{3}$ : sulfonation temperature, $\mathrm{X}_{4}$ : sulfonation time 
In this study, $X_{3}, X_{4}, X_{1} X_{3}, X_{3} X_{4}$ and $X_{3}^{2}$ are the significant model terms. In addition to that, the coefficient of determination, $R^{2}$ value was evaluated to test the model fitness. In this case, the $R^{2}$ value was found to be 0.9121 , which indicated that the model could explain $91.21 \%$ of the variability. Apart from that, an adequate precision value greater than 4 is desirable to measure the signal-to-noise ratio. In this instance, adequate precision value of 10.77 was obtained that indicate sufficient value which means this model can be used to navigate the design space. Further evaluation on the adequacy of the model was evaluated by parity plot of experimental and predicted data as given by Fig. 4. From the Fig.4, the randomly scattering points close to the diagonal line indicated that there is a good agreement between the observed and predicted value.

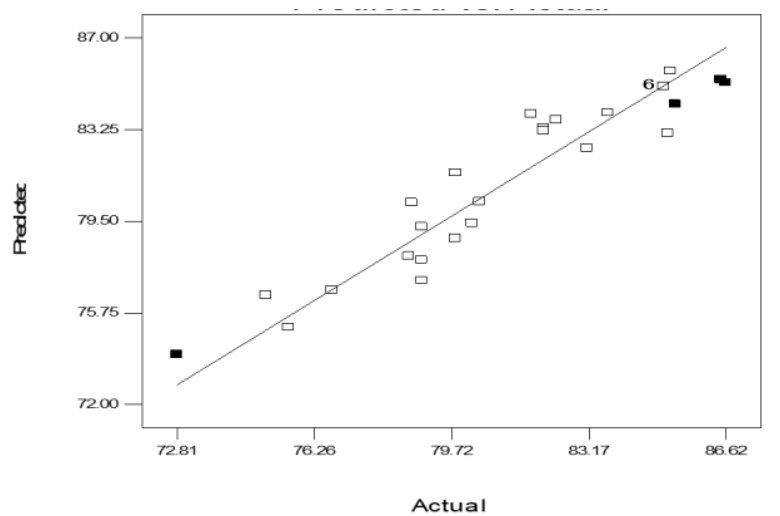

\section{Fig. 4: Predicted vs. actual plot for solid acid catalyst preparation}

\section{Influences of the Catalyst Preparation Conditions}

Fig. 5 illustrates the 3D surface plots for interaction effect of the catalyst activity toward FAME conversion. The interaction effect was determined by evaluating two factors as independent variables whilst the others were set to zero level. The significant interaction between carbonization temperature and carbonization time is depicted in Fig. 5(a). Both factors contribute a positive effect on FAME conversion. Higher carbonization temperature and longer carbonization time produced a soft aggregated, cross-linked polymer that is susceptible to be sulfonated at highest degree thus produce highly efficient solid acid catalyst [29].
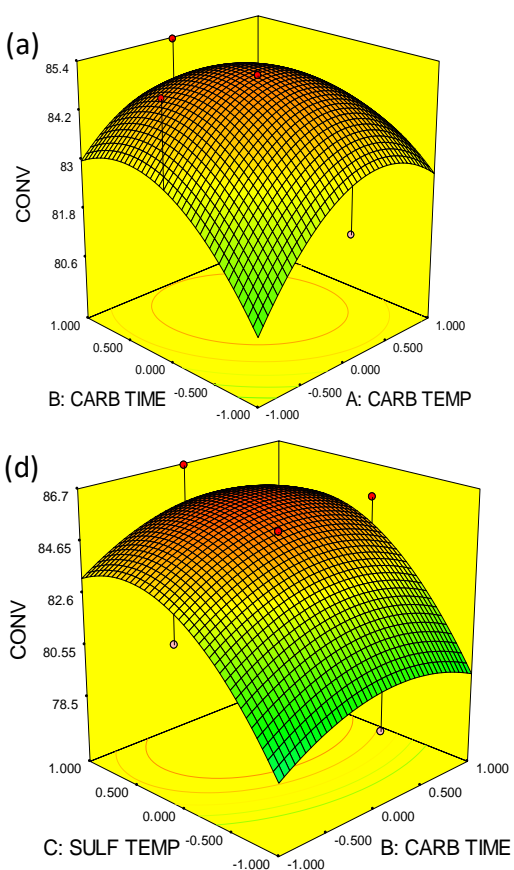
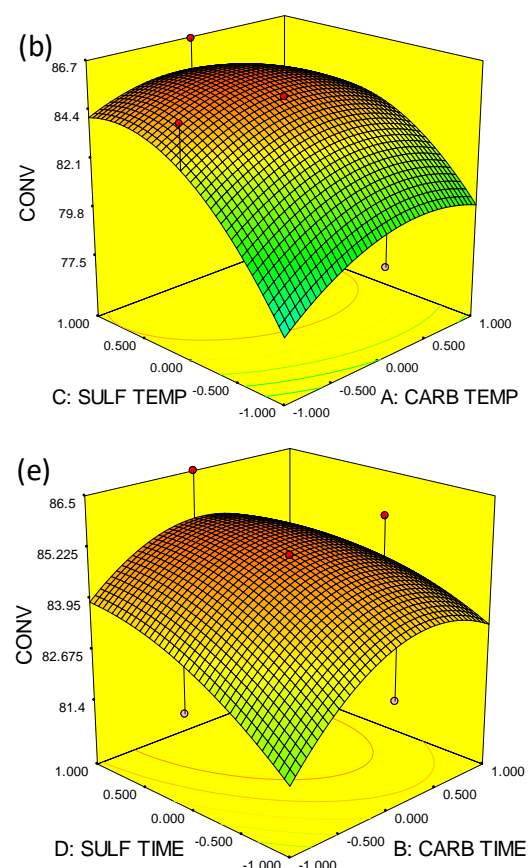
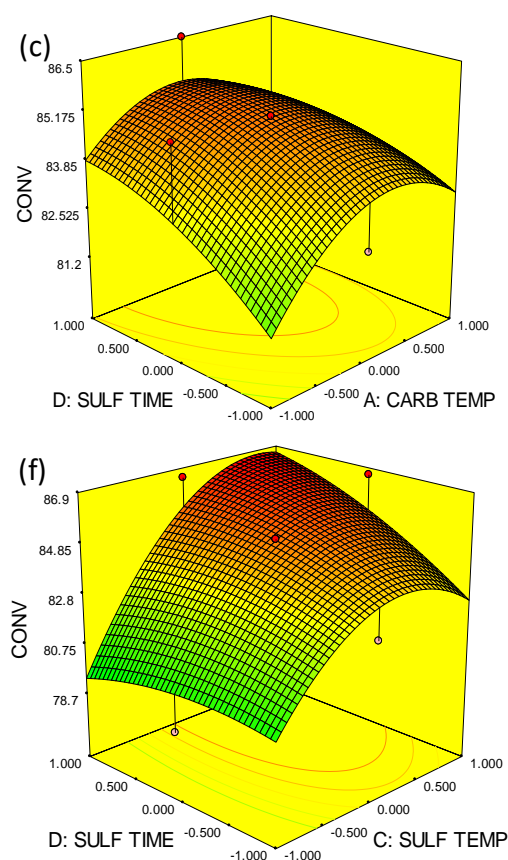

Fig. 5: 3D Surface plots between catalyst preparation variables (a) Carbonization temperature and carbonization time (b) Carbonization temperature and sulfonation temperature (c) Carbonization temperature and sulfonation time (d) Carbonization time and sulfonation temperature (e) Carbonization time and sulfonation time (f) Sulfonation temperature and sulfonation time 


\section{INFLUENCE OF CATALYST PREPARATION CONDITIONS ON COCONUT SHELL-DERIVED SOLID ACID CATALYST PERFORMANCE FOR TRANSESTERIFICATION}

Fig. 5(b) shows the interaction effect between carbonization temperature and sulfonation temperature on FAME conversion. Higher FAME conversion was obtained with higher loading in both factors. Higher sulfonation temperature favours the anchoring of $-\mathrm{SO}_{3} \mathrm{H}$ group on the catalyst surface. As a result, higher numbers of catalytic active sites are available for the reaction to take place [30], [31]. The combined effect of carbonization temperature and sulfonation time on FAME conversion is presented in Fig. 5(c). The FAME conversion is increased when higher loading of carbonization temperature and sulfonation time were employed. Longer holding time allows better incorporation of $-\mathrm{SO}_{3} \mathrm{H}$ group onto the carbon skeleton of the prepared catalyst [32]. Fig. 5 (d) depicts the interaction of carbonization time and sulfonation temperature on FAME conversion. Both factors displayed a positive influence on the conversion however the effect of sulfonation temperature is more pronounced compared to carbonization temperature.

The interaction effect of carbonization time and sulfonation time on FAME conversion is depicted in Fig. 5(e) where both factors contribute significantly to the conversion. However, prolonged holding time in carbonization and sulfonation process negatively affected the catalyst performance as can be seen in the plot. This might be explained by the fact that longer carbonization time might lead to the formation of rigid structure of carbon catalyst [30]. It will hinder the anchoring of $\mathrm{SO}_{3} \mathrm{H}$ onto the catalyst surface leading to catalyst inefficiency [24]. Fig. 5(f) illustrates the surface plots for the interaction effect of sulfonation temperature and sulfonation time. It can be seen from the Fig. that both factors positively influence the FAME conversion.
Nevertheless, sulfonation temperature presented greater influence to the conversion of biodiesel compared to sulfonation time. Higher temperature improves the kinetic energy of sulfonic ions allowing more of them to be attached to the carbon surface [33]. Hence, FAME conversion is significantly increased.

\section{Optimal Conditions}

The optimal catalyst preparation conditions were determined using Design-Expert software. The optimization criteria were set for all the factors and response. The goal was set for "maximize" the FAME conversion while "minimize" was set for all four factors involved. The reason for this setting is to achieve highest possible biodiesel conversion at low operating conditions to reduce the cost and energy required for this process. The optimal catalyst preparation conditions for SAC were found to be as follows: carbonization temperature 469.97 ${ }^{\circ} \mathrm{C}$, carbonization time $3.37 \mathrm{~h}$, sulfonation temperature $99.14{ }^{\circ} \mathrm{C}$ and sulfonation time $7.11 \mathrm{~h}$. Theoretical conversion to biodiesel predicted under the above conditions was $83.77 \%$. A validation test was conducted to validate the adequacy of the predicted optimal solutions. An average FAME conversion value of $82.62 \pm$ $0.256 \%$ with small percentage error $(<2 \%)$ was obtained. Thus, it confirmed the efficacy of the quadratic model to predict the optimal conditions for this process.

\section{E. Palm Biodiesel Properties}

Table 5 summarizes the properties of the produced palm biodiesel catalysed by SAC in this study. The biodiesel properties were compared to the international biodiesel standards of ASTM and European.

Table 5: Biodiesel properties of palm biodiesel catalysed by SAC

\begin{tabular}{|c|c|c|c|}
\hline Parameter & Palm Biodiesel & Biodiesel Standard & Parameter \\
\hline & & ASTM D6751 & EN 14214 \\
\hline Cetane number & 50.7 & $47 \mathrm{~min}$ & $51 \mathrm{~min}$ \\
\hline Density $\left(\mathrm{g} / \mathrm{cm}^{3}\right)$ & 0.8953 & $0.82-0.90$ & $0.86-0.90$ \\
\hline Kinematic viscosity $\left(\mathrm{mm}^{2} / \mathrm{s}\right)$ & 5.726 & $1.9-6.0$ & $3.5-5.0$ \\
\hline Moisture content $(\%)$ & 0.08 & 0.05 & 0.075 \\
\hline Calorific value $(\mathrm{MJ} / \mathrm{kg})$ & 26.82 & 39.2 & $\mathrm{NS}$ \\
\hline
\end{tabular}

Cetane number $(\mathrm{CN})$ is commonly used as an indicator for the determination of diesel fuel quality, especially the ignition quality [34]-[37]. The $\mathrm{CN}$ value of palm biodiesel was found to be at 50.7 which fulfilled the requirement set by both standards. The density of derived palm biodiesel was found to be at $0.8953 \mathrm{~g} / \mathrm{cm}^{3}$, within the allowable limit set by ASTM D6751 standard. Palm biodiesel shows an appropriate viscosity value of 5.726 $\mathrm{mm}^{2} / \mathrm{s}$. The low viscosity indicates that the biodiesel will provide a smooth engine operation and improve engine life [38]. However, slightly higher moisture content was observed in palm biodiesel. This may be ascribed to the presence of traces of water molecule that is not completely dried off prior to the analysis. The calorific value of palm biodiesel was found to be lower than the acceptable limit. This might be due to the presence of unreacted triglyceride and methanol in the biodiesel product [17].

\section{CONCLUSION}

The influence of catalyst preparation conditions on catalyst activity has been thoroughly investigated in this study. Based on the parametric study using the RSM method, the sulfonation process gives a significant effect on the catalytic activity of the solid acid catalyst. Sulfonation temperature $\left(X_{3}\right)$ and sulfonation time $\left(X_{4}\right)$ presented a significant model term as evaluated by ANOVA analysis. These factors play an important role in producing a solid acid catalyst with high catalytic ability. On top of that, this study shows the potential application of biomass or waste material to be converted into a useful and valuable end product such as a solid acid catalyst. 


\section{ACKNOWLEDGMENT}

The authors would like to acknowledge the MyBrain15 scholarship provided by the Ministry of Higher Education, Malaysia and research financial support from FRGS/1/2014/STWN01/UNISZA/02/2).

\section{REFERENCES}

1. M. H. M. Ashnani, A. Johari, and H. Hashim, "A source of renewable energy in Malaysia, why biodiesel?" Renewable and Sustainable Energy Reviews, 35, 2014, pp. 244-257.

2. M. Borges, and L. Díaz, "Recent developments on heterogeneous catalysts for biodiesel production by oil esterification and transesterification reactions: A review," Renewable and Sustainable Energy Reviews, 16(5), 2012, pp. 2839-2849.

3. A. Ahmad, N. Yasin, C. Derek, and J. Lim, "Microalgae as a sustainable energy source for biodiesel production: A review," Renewable and Sustainable Energy Reviews, 15(1), 2011, pp. 584593.

4. M. K. A. Kamarudin, M. E. Toriman, N. H. Sulaiman, F. M. Ata, M. B. Gasim, A. Muhamad, W. A. Yusoff, M. Mokhtar, M. A. Amran, and N. A. Abd Aziz, "Classification of tropical river using chemometrics technique: Case study in Pahang River, Malaysia," Malaysian Journal of Analytical Sciences, 19(5), 2015, pp. 1001-1018.

5. M. E. Toriman, M. B. Gasim, Z. Yusop, I. Shahid, S. A. S. Mastura, P. Abdullah, M. Jaafar, N. A. A. Aziz, M. K. A. Kamarudin, O. Jaafar, O. Karim, H. Juahir, and N. R. Jamil, "Use of $137 \mathrm{CS}$ activity to investigate sediment movement and transport modeling in river coastal environment," American Journal of Environmental Sciences, 8(4), 2012, pp. 417-423.

6. D. Leung, $\mathrm{X}$. Wu, and $\mathrm{M}$. Leung, "A review on biodiesel production using catalyzed transesterification," Applied Energy, 87(4), 2010, pp. 1083-1095.

7. M. K. A. Kamarudin, M. E. Toriman, H. Juahir, A. Azid, M. B. Gasim, A. S. M. Saudi, R. Umar, N. H. Sulaiman, F. M. Ata, A. D. Mustafa, M. A. Amran, W. A. Yusoff, and F. Azaman, "Assessment of river plan change using RS and GIS technique," Jurnal Teknologi, 76(1), 2015, pp. 3138.

8. C. Deshmane, M. Wright, A. Lachgar, M. Rohlfing, Z. Liu, J. Le, and B. Hanson, "A comparative study of solid carbon acid catalysts for the esterification of free fatty acids for biodiesel production. Evidence for the leaching of colloidal carbon," Bioresource Technology, 147, 2013, pp. 597-604.

9. W. Y. Lou, Q. Guo, W. J. Chen, M. H. Zong, H. Wu, and T. J. Smith, "A highly active bagasse-derived solid acid catalyst with properties suitable for production of biodiesel," Chemistry and Sustainability, 5, 2012, pp. 1533-1541.

10. S. H. Y. S. Abdullah, H. Juahir, A. Azid, R. Umar, N. H. M. Hanapi, H. Khatoon, and A. Endut, "A review of biomass-derived solid acid catalyst for biodiesel production," Renewable and Sustainable Energy Reviews, 70, 2016, pp. 1040-1051.

11. Y. M. Sani, A. O. Raji-Yahya, P. A. Alaba, A. R. A. Aziz, and W. M. A. Daud, "Palm frond and spikelet as environmentally benign alternative solid acid catalysts for biodiesel production," BioResources, 10(2), 2015, pp. 3393-3408. FRGS Research Grant (Project No. RR067, Project Code

12. N. H. Farah, H. Salmah, and M. Marliza, "Effect of butyl methacrylate on properties of regenerated cellulose coconut shell biocomposite films," Procedia Chemistry, 19, 2016, pp. 335-339.

13. M. N. Z. Moni, S. A. Sulaiman, Y. S. Raja, K Karunamurthy, M. Inayat, and M. A. Bou-Rabee, "Investigation of the relationship between moisture content and density of selected Malaysian biomass," Journal of Mechanical Engineering and Sciences, 10(2), 2016, pp. 2111-2025.

14. S. M. Shafie, T. M. I. Mahlia, H. H. Masjuki, and A. A. Yazid, "A review on electricity generation based on biomass residue in Malaysia," Renewable and Sustainable Energy Reviews, 16(8), 2012, pp. 5879-5889.

15. A. W. Krowiak, K. Chojnacka, D. Podstawczyk, A. Dawiec, and K. Pokomeda, "Application of response surface methodology and artificial neural network methods in modelling and optimization of biosorption process," Bioresource Technology, 160, 2014, pp. 150160.

16. F. Ghorbani, H. Younesi, S. M. Ghasempouri, A. A. Zinatizadeh, M. Amini, and A. Daneshi, "Application of response surface methodology for optimization of cadmium biosorption in an aqueous solution by Saccharomyces cerevisiae," Chemical Engineering Journal, 145, 2008, pp. 267-275.

17. A. Endut, S. H. Y. S. Abdullah, N. H. M. Hanapi, S. H. A. Hamid, F. Lananan, M. K. A. Kamarudin, R. Umar, and H. Khatoon, "Optimization of biodiesel production by solid acid catalyst derived from coconut shell via response surface methodology," International Biodeterioration and Biodegradation, 124, 2017, pp. 250-257.

18. S. V. Orta, J. Lee, and A. Harvey, "Evaluation of FAME production from wet marine and freshwater microalgae by in situ transesterification," Biochemical Engineering Journal, 76, 2013, pp. 8389.

19. M. Huang, J. Luo, Z. Fang, and H. Li, "Biodiesel production catalyzed by highly acidic carbonaceous catalysts synthesized via carbonizing lignin in sub- and super-critical ethanol," Applied Catalysis B: Environmental, 190, 2016, pp. 1103-1114.

20. A. M. Abu-Jrai, F. Jamil, A. H. Al-Muhtaseb, M. Baawain, L. Al-Haj, M. Al-Hinai, M. Al-Abri, and S. Rafiq "Valorization of waste date pits biomass for biodiesel production in the presence of green carbon catalyst," Energy Conversion and Management, 135, 2017, pp. 236243.

21. M. L. Tao, H. Y. Guan, X. H. Wang, Y. C. Liu and R. F. Louh, "Fabrication of sulfonated carbon catalyst from biomass waste and its use for glycerol esterification," Fuel Processing Technology, 138, 2015, pp. 355-360.

22. M. Zhang, A. Sun, Y. Meng, L. Wang, H. Jiang, and G. Li, "Catalytic performance of biomass carbon-based solid acid catalyst for esterification of free fatty acids in waste cooking oil," Catalyst Survey Asia, 19, 2015, pp. 61-67.

23. M. Li, Y. Zheng, Y. Chen, and X. Zhu, "Biodiesel production from waste cooking oil using a heterogeneous catalyst from pyrolyzed rice husk," Bioresource Technology, 154, 2014, pp. 345-348.

24. R. Luque, A. Pineda, J. C. Colmenares, J. M. Campelo, A. A. Romero, J. C. Serrano-Riz, and J. Cot-Gores, "Carbonaceous residues from biomass gasification as catalysts for biodiesel production," Journal of Natural Gas Chemistry, 21(3), 2012, pp. 246-250.

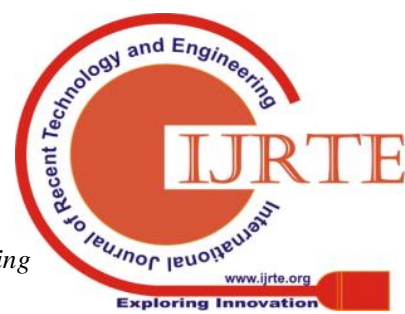


25. W. Roschat, M. Kacha, B. Yoosuk, T. Sudyoadsuk, and V. Promarak, "Biodiesel production based on heterogeneous process catalyzed by solid waste coral fragment," Fuel, 98, 2012, pp. 194-202.

26. Q. Shu, Z. Nawaz, J. Gao, Y. Liao, Q. Zhang, D. Wang, and J. Wang, "Synthesis of biodiesel from a model waste oil feedstock using a carbon-based solid acid catalyst: Reaction and separation," Bioresource Technology, 101(14), 2010, pp. 5374-5384.

27. O. Ayodele, and F. Dawodu, "Production of biodiesel from Calophyllum inophyllum oil using a cellulose-derived catalyst," Biomass and Bioenergy, 70, 2014, pp. 239-248.

28. F. L. Pua, Z. Fang, S. Zakaria, F. Guo, and C. H. Chia, "Direct production of biodiesel from high-acid value Jatropha oil with solid acid catalyst derived from lignin," Biotechnology for Biofuels, 4(1), 2011, pp. 56-63.

29. F. E. Babadi, S. Hosseini, S. M. Soltani, M. K. Aroua, A. Shamiri, and M. Samadi, "Sulfonated beet pulp as solid catalyst in one-step esterification of industrial palm fatty acid distillate," Journal of the American Oil Chemists' Society, 93(3), 2016, pp. 319-327.

30. K. Malins, V. Kampars, J. Brinks, I. Neibolte, and R. Murnieks, "Synthesis of activated carbon based heterogenous acid catalyst for biodiesel preparation," Applied Catalysis B: Environmental, 176, 2015, pp. 553558.

31. F. Guo, Z. Xiu, and Z. Liang, "Synthesis of biodiesel from acidified soybean soapstock using a ligninderived carbonaceous catalyst," Applied Energy, 98, 2012, pp. 47-52.

32. J. Kastner, J. Miller, D. Geller, J. Locklin, L. Keith, and T. Johnson, "Catalytic esterification of fatty acids using solid acid catalysts generated from biochar and activated carbon," Catalysis Today, 190(1), 2012, pp. 122-132.

33. S. Kang, J. Ye, and J. Chang, "Recent advances in carbonbased sulfonated catalyst: Preparation and application," International Review of Chemical Engineering, 5(2), 2013, pp. 133-144.

34. G. Chen, and B. Fang, "Preparation of solid acid catalyst from glucose-starch mixture for biodiesel production," Bioresource Technology, 102(3), 2011, pp. 2635-2640.

35. F. Dawodu, O. Ayodele, J. Xin, S. Zhang, and D. Yan, "Effective conversion of non-edible oil with high free fatty acid into biodiesel by sulfonated carbon catalyst," Applied Energy, 114, 2014, pp. 819-826.

36. R. Gottipati, Preparation and characterization of microporous activated carbon from biomass and its application in the removal of chromium (VI) from aqueous phase. PhD thesis, Odisha: National Institute of Technology, 2012.

37. E. M. Fakhry, and D. M. El Maghraby, "Fatty acids composition and biodiesel characterization of Dunaliella salina," Journal of Water Resources and Protection, 5, 2013, pp. 894-899.

38. M. Kumar, and M. P. Sharma, "Optimization of transesterification of Chlorella protothecoides oil to biodiesel using Box-Behnken design method," Waste and Biomass Valorization, 7(5), 2016, pp. 1105-1114. 